Check for updates

Portsmouth

Cite this as: BMJ 2021;374:n1871 http://dx.doi.org/10.1136/bmj.n1871 Published: 22 July 2021

\section{Covid-19:1.5 million children have been orphaned by pandemic, study estimates}

Luke Taylor

Covid-19 has not only killed more than four million people worldwide but has also left at least one million orphans, a study published in the Lancet has estimated. ${ }^{1}$

A person under 18 loses a caregiver to covid every 12 seconds, say the study's authors, and the toll continues to grow, even as the pandemic recedes.

"For every two covid-19 deaths worldwide, one child is left behind to face the death of a parent or caregiver," said Susan Hillis, one of the study's lead authors and a member of the US Centers for Disease Control and Prevention's Covid-19 Response Team. "By April 30, 2021, these 1.5 million children had become the tragic overlooked consequence."2

The study was conducted by researchers at some of the world's leading research institutions, including Oxford University, the World Health Organization, and Harvard Medical School. By modelling mortality data and national fertility statistics in 21 countries they found that at least one million children would have experienced the death of one or both of their parents during the first 14 months of the pandemic.

That estimate is a lower bound, and the hidden toll is likely far higher, said Juliette Unwin, research fellow at Imperial College London and one of the study's lead authors. "Tragically, many demographic, epidemiological, and healthcare factors suggest that the true numbers affected could be orders of magnitude larger," she said.

\section{Global variation}

The phenomenon has also hit harder in poorer nations, where the pandemic continues to rage and children continue to lose guardians. "In the months ahead variants and the slow pace of vaccination globally threaten to accelerate the pandemic, even in already incredibly hard hit countries, resulting in millions more children experiencing orphanhood," said Unwin.

In England and Wales 8495 minors had lost a parent by the end of April 2021, equal to 0.6 per 1000 children, the study concluded.

In South Africa 4.4 children in every 1000 have been orphaned because of covid; in Mexico, 3.3 in 1000; in Brazil, 2.1 in 1000, and in the US, 1.4 in 1000.

Peru is the worst affected nation in the world, as 92 ooo of its children have lost a parent-approximately one in every 100.

Worldwide, children were around five times more likely to lose a father than a mother, as more men die from covid than women. As well as having a higher risk of being institutionalised in an orphanage or care home, children who lose a parent or caregiver are more likely to experience broader adverse effects on their health, safety, and wellbeing in the short and long term.

A multipronged approach, from financial aid and schooling to healthcare and counselling, must be enacted urgently to minimise long term damage, said Seth Flaxman, one of the study's authors at Imperial College. ${ }^{2}$

"The hidden pandemic of orphanhood is a global emergency, and we can ill afford to wait until tomorrow to act," he said. "Tomorrow is too late for the child institutionalised in an orphanage, who will grow up profoundly damaged by the experience.

"We urgently need to identify the children behind these numbers and strengthen monitoring systems, so that every child can be given the support they need to thrive."

\section{Hillis SD, Unwin HIT Chen Y et al. Global minimum estimates of children affected by covid-19-associated orphanhood and deaths of caregivers: a modelling study. Lancet 2021 (published online 20 Jul). doi: 10.1016/S0140-6736(21)01253-8. https://www.thelancet.com/jour- nals/lancet/article/PIIS0140-6736(21)01253-8/fulltext \\ 2 The Lancet: 1.5 million children worldwide have lost parent, grandparent, caregiver due to covid-19. EurekAlert 2021 Jul 20. https://eu- rekalert.org/pub_releases/2021-07/tl-tl1071921.php.}

This article is made freely available for use in accordance with BMJ's website determined by BM]. You may use, download and print the article for any lawful, non-commercial purpose (including text and data mining) provided that all copyright notices and trade marks are retained. terms and conditions for the duration of the covid-19 pandemic or until otherwise 